\title{
29 Why did mitochondria become synonymous with $\mathrm{O}_{2}$ ?
}

In order to appreciate the impact that eukaryotic anaerobes have had upon views of eukaryotic evolution, it is helpful to briefly retrace the steps to see how it came to be that the physiology of eukaryotic anaerobes became an evolutionarily important issue in the first place. If we do not delve deeply into different theories about mitochondrial evolution here - reviewed in (Zimorski et al. 2014) and (Martin et al. 2015) - it is because there are just too many of them to cover succinctly and (almost) none of them addressed the evolution of eukaryotic anaerobes, anaerobic mitochondria in particular. Historical developments in the field concerning the evolutionary significance of anaerobic mitochondria start with the idea that mitochondria were endosymbionts in the first place. A number of authors, including O'Rourke (2010) and many easily searchable internet sites, attribute the idea that mitochondria arose through symbiosis to Richard Altmann in his book Die Elementarorganismen und ihre Beziehung zu den Zellen (1890). That is however not correct because in that book, Altmann writes about "bioblasts" (Bioblasten), which he described as granules, visible in fixed material under the light microscope, that represent an organizational state of matter intermediate between that of a molecule and that of an organelle. For Altmann, everything in the cell was made of bioblasts, including metaphase chromosomes. He was not suggesting that chromosomes are made of mitochondria, he was suggesting that chromosomes were made of bioblasts, which in today's terms might equate to macromolecular complexes. Nowhere in the 1890 book does Altmann mention mitochondria, obviously, because the term mitochondria was introduced well after 1890, by Benda (1898). Nor does Altmann mention their older name, chondriosomes, nor does he make a suggestion about their possible bacterial nature. Altmann's Bioblasten are not mitochondria.

Endosymbiotic theory generally starts with Mereschkowsky's theory for the origin of plastids (1905). Endosymbiotic theories for the origin of mitochondria do not, however, start with Mereschkowsky, because Mereschkowsky neither entertained nor proposed a symbiotic origin of mitochondria. He did think that there was a symbiosis that preceded the plastid in the evolution of the plant and animal lineages, and he was convinced that symbiosis marked the origin of the physiological attributes of cells that we today attribute to mitochondria, but he thought that the organelle responsible for those traits was the nucleus, which in his view was derived from an endosymbiotic bacterium (Mereschkowsky 1905). He furthermore thought that the nucleus in fungi arose autogenously (not from an endosymbiont) such that the nucleus in fungi and other eukaryotes had separate origins, one endosymbiotic in origin, the other not, a line of reasoning that caused him to miss the prokaryote eukaryote dichotomy. The prokaryote eukaryote dichotomy is, in turn, usually attributed to a 407-page 1937 book by Edouard Chatton that is extremely rare, of which we have no 
copy and hence will not cite. Indeed, as beautifully explained by Katscher (2004), the situation is more complicated because Chatton (1925) introduced the terms Eucaryotes and Procaryotes, but only in diagrams in the very final pages of the article, the initial occurrence being shown in Figure 31, while the 1937 book uses the term Eucaryotes and Procaryotes only once (Katscher 2004), in the text. The broader meaning that became attached to the terms that Chatton introduced, namely the prokaryote eukaryote divide that is now recognized, was provided much later by Stanier and van Niel (1962). A look at the 1925 scheme by Chatton (Figure 31), the page on which the term Eucaryotes entered the literature, reveals a number of protists with anaerobic physiology. The later, modern spelling (eukaryotes with a k) is justified because the transcription of the original ancient Greek karyon (for "nut") prescribes a k.

There were endosymbiotic ideas about the evolution of mitochondria before Margulis's first paper on the topic, which she published under the name Sagan (Sagan 1967). In his 1918 book Les Symbiotes, Paul Portier published ideas on the symbiotic origin of mitochondria in French, as discussed in Sapp (1994) and Archibald (2014). The contributions by Ivan Wallin (1925) should be mentioned, as he was explicit about the bacterial nature of mitochondria and even went so far as to suggest that genes would be transferred from the endosymbiont to the host, at a time when it was not known what genes were or what their chemical composition was. We recall that people did not know how ATP was made in mitochondria until the 1970s, just after DNA was being discovered in organelles (Nass and Nass 1963). We also recall that endosymbiotic theory was not widely accepted until the 1980s. An in-depth survey of the very early history of symbiosis is given in a book by Geus and Höxtermann (2007), but published in German. It was there that we found mention of Katscher (2004), which provides valuable and thorough coverage of the terms prokaryote and eukaryote but is almost never cited.

Coming back to oxygen, Margulis's revival of endosymbiotic theory had it that eukaryotes are ancestrally aerobes, it matched with the view of atmospheric evolution that was current at the time (Cloud 1968). Her version of endosymbiotic theory ended up in college microbiology classrooms (including our own). It said that eukaryotes were ancestrally bacterium-eating (phagotrophic) and their mitochondria arose with rising $\mathrm{O}_{2}$ levels 2 billion years ago at a time when oxygen started accumulating in the atmosphere (later known as the great oxidation event): "It is suggested that the first step in the origin of eukaryotes from prokaryotes was related to survival in the new oxygen-containing atmosphere: an aerobic prokaryotic microbe (i.e. the protomitochondrion) was ingested into the cytoplasm of a heterotrophic anaerobe." (Sagan 1967, p. 228). This basic idea is found in many other contributions on the topic (Andersson et al. 1998; Andersson and Kurland 1999; Cavalier-Smith 2002). It is implicit in many others, so implicit that it is often not even spelled out as an assumption. Biologists familiar with anaerobic physiology in specific groups of eukaryotes steered clear of the topic of endosymbiotic origin of mitochondria (Fenchel and Finlay 1995; Hochachka and Somero 2002), probably because 
76

ÉD. CHATTON

ESSAI DE CLASSIFICATION DES PROTISTES(1)

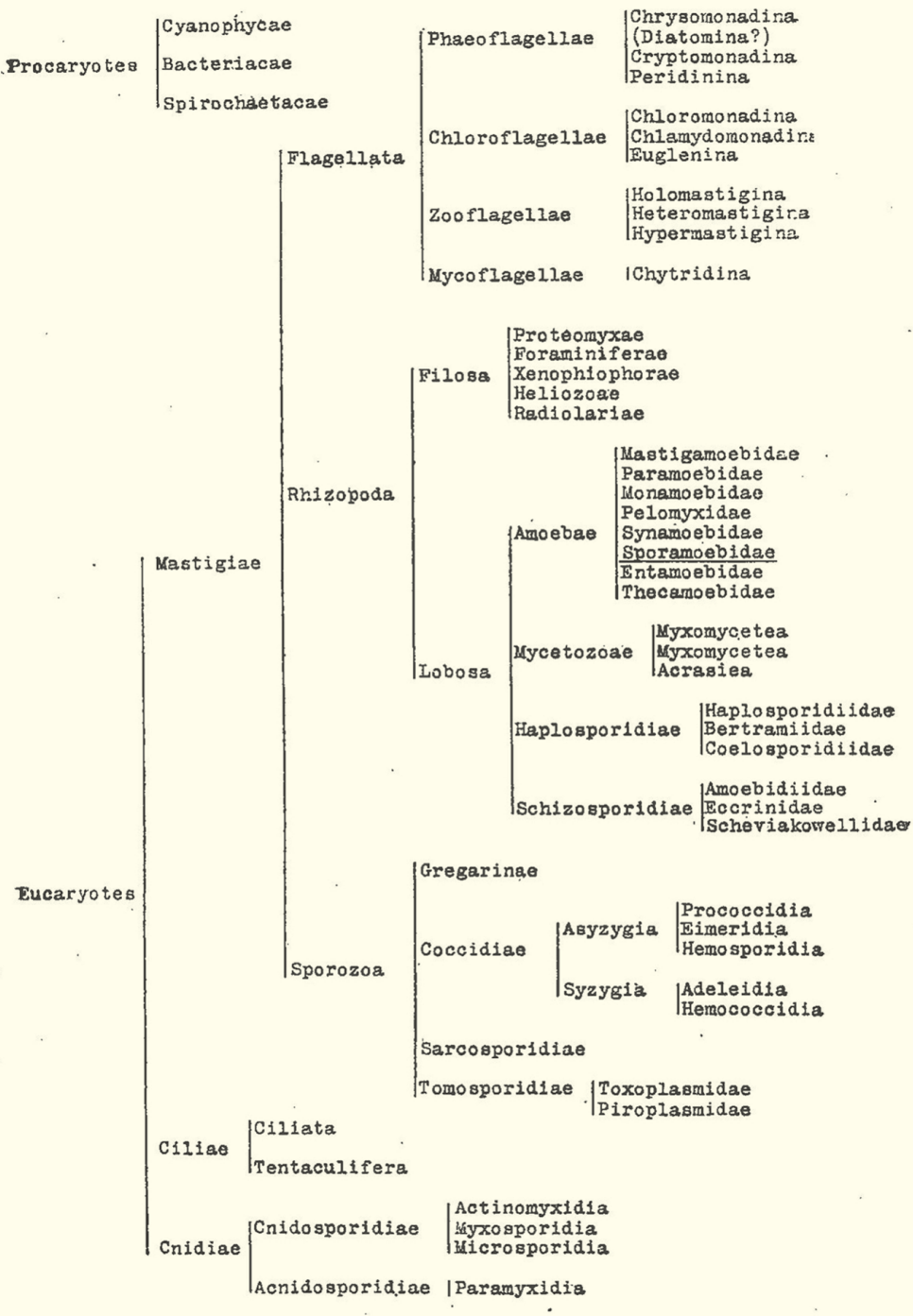

(1) La subdivision n'a été poussée jusqu'aux familles que dans quelques groupes. Il ne s'agissait pas de dresser ici un tableau complet et détaillé de la classification de Protistes, mais de résumer et d'illustrer les vues exposées dans. ce mémoire et de montrer en quoi elles diffèrent des notions classiques. 
anaerobic mitochondria did not fit into the mold that Margulis' version of endosymbiotic theory had cast and because there were no physiologically founded alternatives available that would account for anaerobic mitochondria.

The host in Margulis's version of endosymbiotic theory, and variants descended from it, was an anaerobic, phagocytosing microbe that could gain protection from toxic oxygen by acquiring an oxygen respiring symbiont. As time passed, so the simplistic version, the symbiotic association would lead to internalization of the aerobic bacteria and direct detoxification of the host's cytoplasm before eventually the endosymbionts became aerobic, respiring mitochondria, which currently generate ATP for eukaryotic cells (Andersson and Kurland 1999). From this traditional line of reasoning came the premise that the endosymbiotic event and formation of aerobic mitochondria represented the evolutionary separation of primitive mitochondrion lacking anaerobic eukaryotes (ancestral) from aerobic eukaryotes with mitochondria (derived). The most explicit and consistent forms of that theory were presented by Margulis (Margulis et al. 2006), although her version of endosymbiosis always had spirochaetes as additional symbionts that, in her view, gave rise to eukaryotic flagella. The flagella part of the theory had no physiological basis and never gained much footing as an explanatory tool in the literature. Though the spirochaete part of her proposal was not widely adopted, her basic idea that the entry of aerobic mitochondria into a phagocytosing fermenter coincided with the advent of an oxygenated atmosphere, and that mitochondria separated anaerobic eukaryotes (ancestral) from aerobic eukaryotes with mitochondria (derived) became the standard model.

Figure 31: Coinage of the terms Procaryotes and Eucaryotes in 1925 on page 76 of Chatton (1925). Source gallica.bnf.fr / Bibliothèque nationale de France. Chlamydomonads, euglenids, chytrids (as flagellates), entamoebids, apicomplexans (toxoplasma), ciliates and microporidia are included in the scheme. According to Katscher (2004), page 76 of Chatton (1925) marks the first appearance of the terms in the literature. As pointed out by Katscher, Chatton was concerned only with protists and did not include higher plants or animals in his scheme, hence one could discuss whether Chatton, like Mereschkowsky, actually missed the prokaryote eukaryote divide that we now recognize, but for a different reason, despite introducing the terms. 